\title{
Painting Architecture: House Paint Pavilion In Detroit Michigan
}

NICHOLAS R. GELPI

Florida International University

This project was commissioned to mark the grand opening of a new arts center and gallery, housed within a renovated fire station in the eastern market neighborhood of Detroit. The existing building which housed the gallery was largely preserved intact, with little modification to its rough walls and exposed concrete floors. As a result the pavilion was conceived of as a freestanding structure which not only created a type of space which was diverse from its surroundings, but also created a new type of surface for displaying art, one that blurred the boundary between the art and architecture itself.

The shape of the pavilion lends it a recognizable identity as a piece of domestic architecture, in which the art hung on its walls has assumed the identity of the structure by overtaking the house, and blurring the boundary between art and architecture. In this way the pavilion challenges the typical modes of art display, by reversing the hierarchy, whereby paintings are typically hung on walls. Here the pavilion emerges out of the compositional folds of the painting itself. What results is an ambiguous figure, almost a house, almost a painting, maybe a sculpture, but not quite the right size. It is de-familiarizing in subtle ways.

Conceived of as an inhabitable painting in the shape of a house, this pavilion was designed to be painted...the familiar form of the pavilion blurs the surfaces between the walls of building and the painting displayed upon it. On the exterior, the painting bleeds through the surface as a series of engraved lines which mimic the appearance of unusually configured exterior house siding.

The pavilion was also intended to exhibit the collaborative process itself. The process of collaboration involved the integration of the architect's form and the artist's composition. Each collaborator worked simultaneously with lines of pattern and folds integrating both into a single immersive field. Small scale sketches were enlarged to the scale of a building in an otherwise absurd act, and fabricated at the domestic scale of a house. This new synthesis in the pavilion serves to blur boundaries and find possibilities for new experiences between art and architecture.

The pavilion was constructed of standard residential wood framing on 16 inch spacing, joined with lasercut steel gusset plates. Birch plywood panels were machined with grooves on the exterior displaying the underlying composition of the interior painting.

Visitors to the gallery observe flat works of art hung on the walls, and when they encounter the freestanding pavilion are invited to enter inside where they become immersed within a 3 dimensional spatial painting. On the exterior, users explore the undulating folds of the plywood surfaces, peering inside through small windows strangely positioned within the compositional engravings of the exterior. Each of the individual openings frames a unique perspective of the pavilion's interior, some low and some tall, creating a variety of unique views extracted from a single composition based on privileged perspectives in space. 

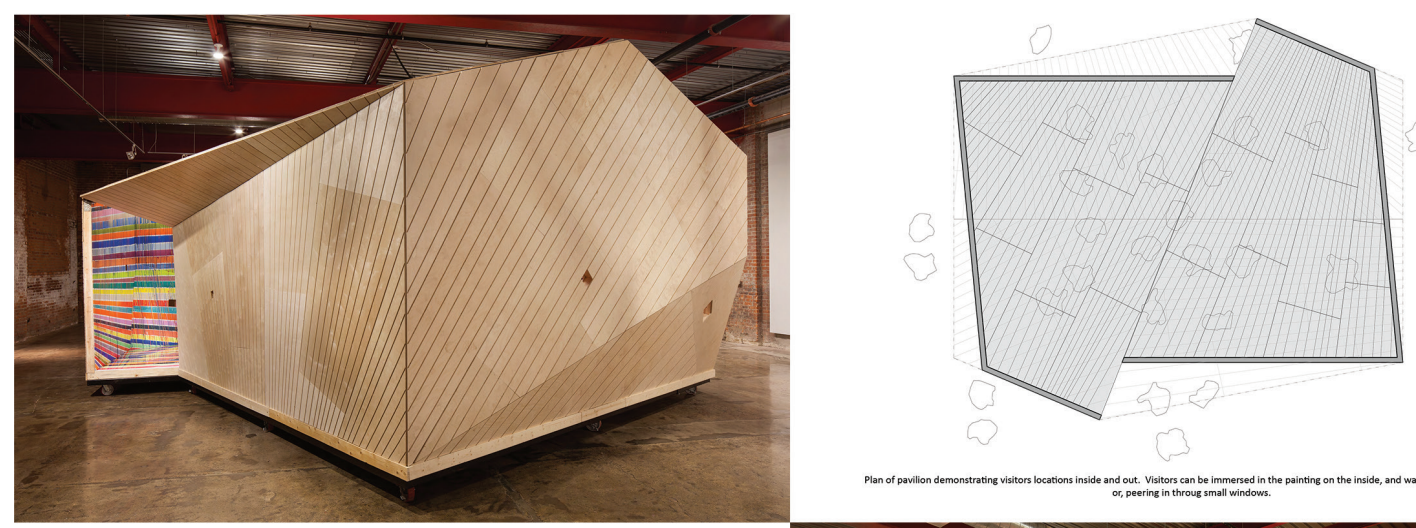

Corner of Pavilion, with engreved lines wrapping around folded cormers.
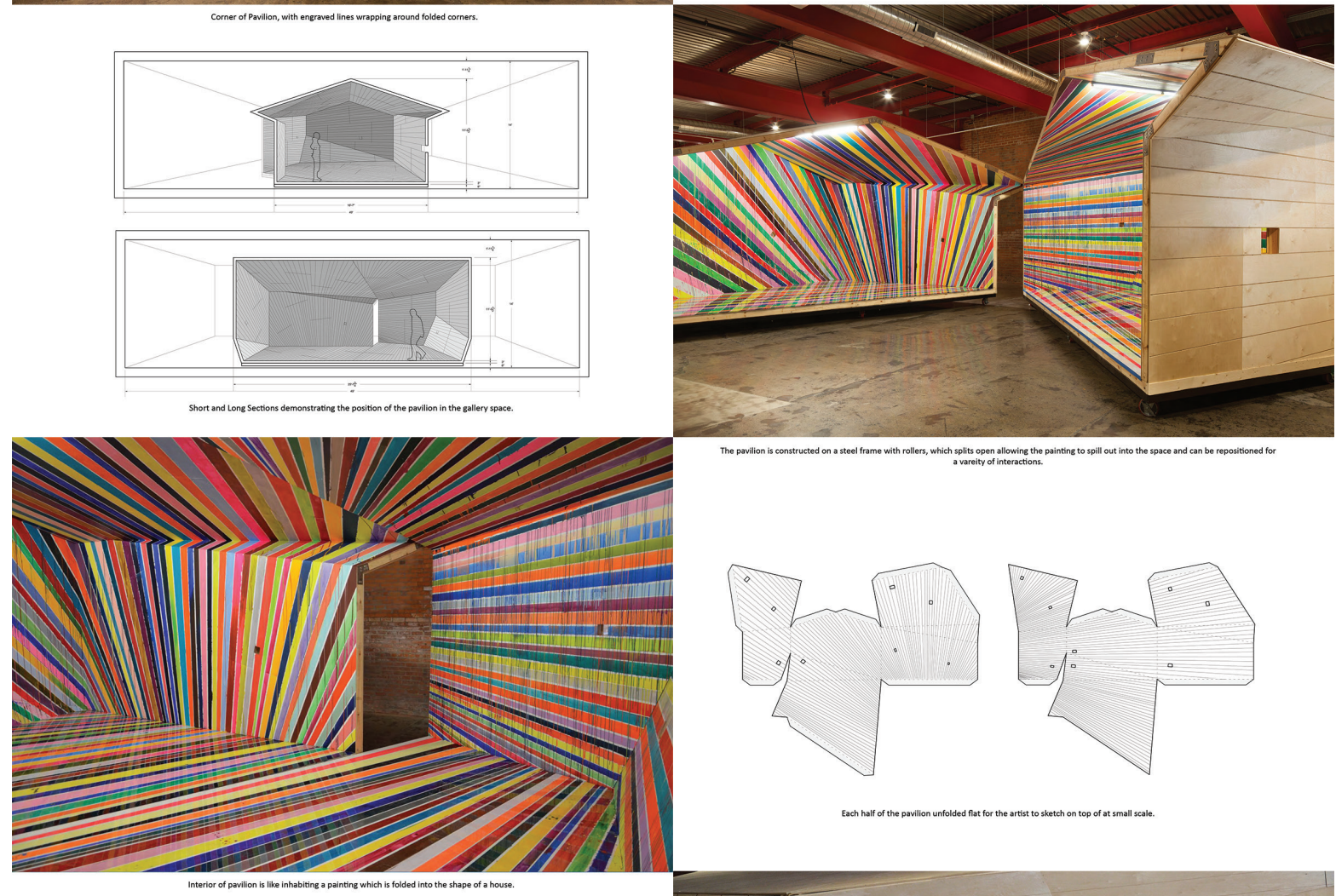

The pavilion is constructed on a steel frame with rollers, which spitis open allowing the painting to spill out into the space and can be repositioned for
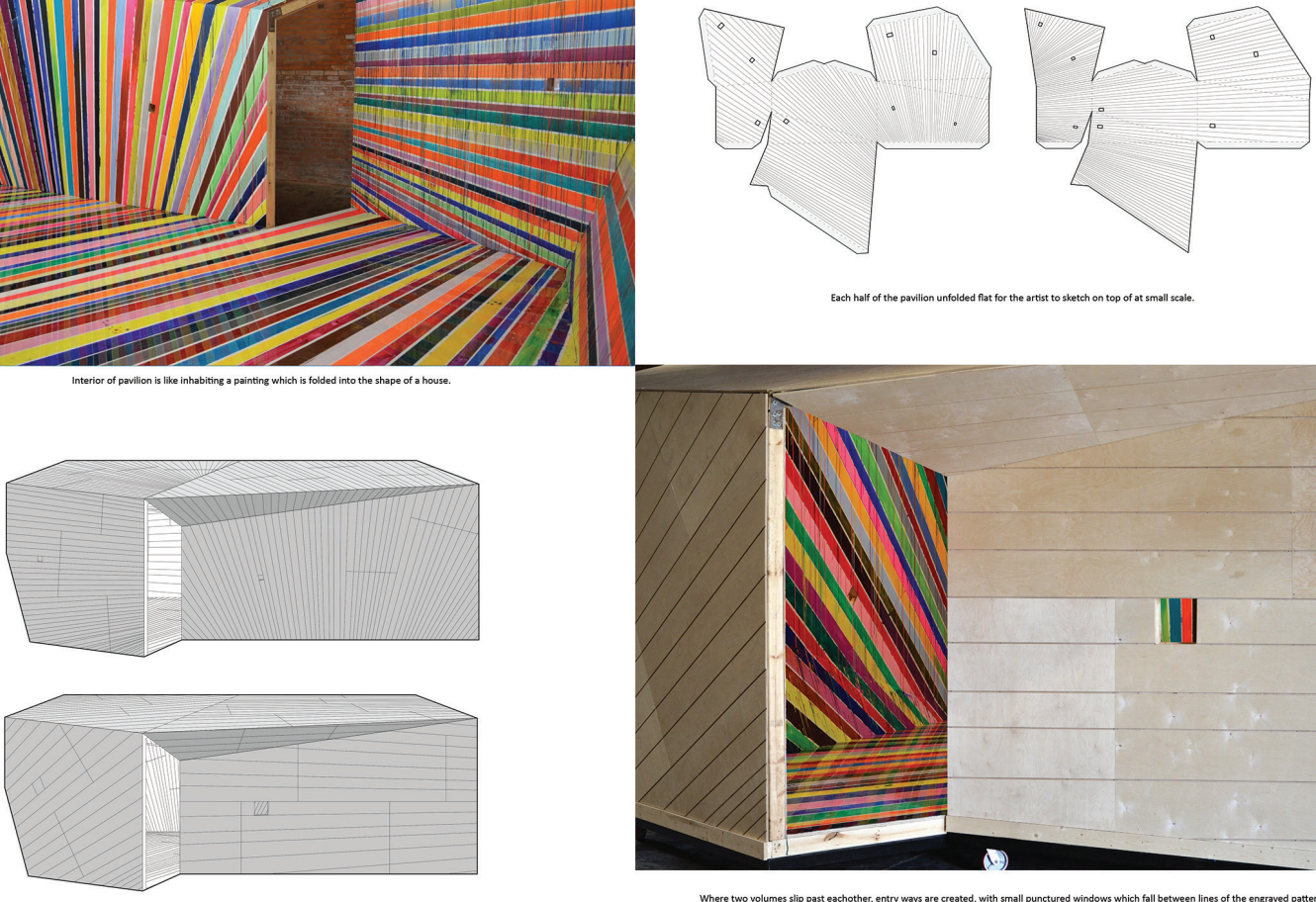

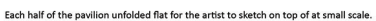

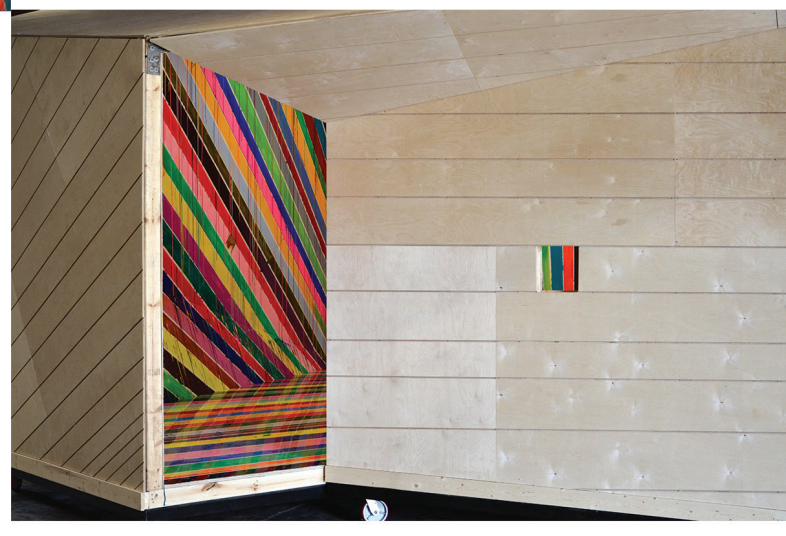

Where two volumes slip past eachother, entry ways sare created, with small punctured windows which fall between lines of the engraved pastern. 